\title{
Personal attitudes towards smoking in a national sample of Aboriginal and Torres Strait Islander smokers and recent quitters
}

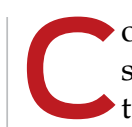
ontemporary theories of smoking and other addictive behaviours see attitudes as one set of forces influencing behaviour. ${ }^{1,2}$ Negative attitudes towards smoking, such as those about its high cost or regret about starting to smoke, are associated with increased interest in quitting and attempts to quit, ${ }^{3-5}$ but perhaps not with sustained abstinence. ${ }^{6,7}$ These attitudes compete with the benefits attributed to smoking, which have been shown to predict continued smoking and relapse..$^{8-10}$ Identifying attitudes that influence behaviour contributes to our understanding of what motivates and sustains quitting. This may differ between social and cultural environments, affecting which tobacco control policies work to reduce smoking., ${ }^{411}$

There is no nationally representative research that explores attitudes towards smoking among Aboriginal and Torres Strait Islander people. It is plausible that part of the reason for the high daily smoking prevalence, which was over double that of the non-Indigenous population in $2012-2013,{ }^{12}$ is that Aboriginal and Torres Strait Islander people hold more positive attitudes and/or fewer negative beliefs about smoking. It is also theorised that thoughts about quitting may be cast aside in stressful circumstances, when motivation shifts from future goals to immediate priorities, ${ }^{2,13}$ which may be seen to be alleviated by benefits of smoking. Benefits of smoking described by Aboriginal and Torres Strait Islander peoples include coping with stress, ${ }^{14-21}$ providing belonging and connectedness, ${ }^{15,17,19-22}$ reinforcing sharing and reciprocity, $15,17,1,21$ and creating opportunities for yarning or talking through problems. . $^{14,15,17,19-21}$ Though concern about the high cost of smoking does not feature heavily in Aboriginal tobacco control literature, it is reported as one of the top

\section{Abstract}

Objectives: To describe attitudes towards smoking in a national sample of Aboriginal and Torres Strait Islander smokers and recent quitters and assess how they are associated with quitting, and to compare these attitudes with those of smokers in the general Australian population.

Design, setting and participants: The Talking About The Smokes project used a quota sampling design to recruit participants from communities served by 34 Aboriginal community-controlled health services and one community in the Torres Strait. We surveyed 1392 daily smokers, 251 nondaily smokers and 78 recent quitters from April 2012 to October 2013.

Main outcome measures: Personal attitudes towards smoking and quitting, wanting to quit, and attempting to quit in the past year.

Results: Aboriginal and Torres Strait Islander daily smokers were less likely than daily smokers in the general Australian population to report enjoying smoking ( $65 \%$ v $81 \%$ ) and more likely to disagree that smoking is an important part of their life ( $49 \% \vee 38 \%)$; other attitudes were similar between the two groups. In the Aboriginal and Torres Strait Islander sample, non-daily smokers generally held less positive attitudes towards smoking compared with daily smokers, and ex-smokers who had quit within the past year reported positive views about quitting. Among the daily smokers, $78 \%$ reported regretting starting to smoke and $81 \%$ reported spending too much money on cigarettes, both of which were positively associated with wanting and attempting to quit; $32 \%$ perceived smoking to be an important part of their life, which was negatively associated with both quit outcomes; and $83 \%$ agreed that smoking calms them down when stressed, which was not associated with the quitting outcomes.

Conclusions: Aboriginal and Torres Strait Islander smokers were less likely than those in the general population to report positive reasons to smoke and held similar views about the negative aspects, suggesting that factors other than personal attitudes may be responsible for the high continuing smoking rate in this population.

motivators to quit among the general Australian population. ${ }^{23}$

Here, we describe attitudes towards smoking among a national sample of Aboriginal and Torres Strait Islander smokers and recent quitters, assess their association with quitting among smokers, and compare these attitudes with those among smokers in the general Australian population.

\section{Methods}

\section{Survey design and participants}

The Talking About The Smokes (TATS) project surveyed 1643 current smokers and 78 ex-smokers who had quit $\leqslant 12$ months previously, from April 2012 to October 2013 (Wave 1, or baseline). The survey design and participants are described in detail elsewhere. ${ }^{24,25}$

Briefly, the study used a quota sampling design to recruit participants from communities served by 34 Aboriginal community-controlled health services (ACCHSs) and one community in the Torres Strait (project sites), which were selected based on the population distribution of Aboriginal and Torres Strait Islander people by state or territory and remoteness. In most sites (30/35), we aimed to interview a sample of 50 smokers or recent quitters (those who had quit within the past 12 months), with equal numbers of men and women, and those aged 18-34 years and $\geqslant 35$ years. The sample sizes were doubled in four large city sites 
and in the Torres Strait community. People were excluded if they did not identify as Aboriginal or Torres Strait Islander, were less than 18 years old, were not usual residents of the area, were staff of the ACCHS, or were deemed unable to complete the survey. In each location, different locally determined methods were used to collect a representative, albeit non-random, sample (eg, surveying Aboriginal or Torres Strait Islander households, opportunistic eventbased sampling, snowball sampling using established contacts).

Interviews were conducted face to face by trained interviewers, almost all of whom were members of the local Aboriginal and Torres Strait Islander community. The survey, entered directly onto a computer tablet, took 30-60 minutes to complete. The baseline sample closely matched the distribution of the 2008 National Aboriginal and Torres Strait Islander Social Survey (NATSISS) by age, sex, jurisdiction and remoteness, and also for number of cigarettes smoked per day (for current daily smokers). However, there were inconsistent differences in some socioeconomic indicators: our sample had higher proportions of unemployed people, but also higher proportions who had completed Year 12 and who lived in more advantaged areas. ${ }^{24}$ A single survey of health service activities was also completed for each site.

The project was approved by three Aboriginal human research ethics committees (HRECs) and two HRECs with Aboriginal subcommittees: Aboriginal Health \& Medical Research Council Ethics Committee, Sydney; Aboriginal Health Research Ethics Committee, Adelaide; Central Australian HREC, Alice Springs; HREC for the Northern Territory Department of Health and Menzies School of Health Research, Darwin; and the Western Australian Aboriginal Health Ethics Committee, Perth.

\section{ITC Project comparison sample}

The TATS project is part of the International Tobacco Control Policy Evaluation Project (ITC Project) collaboration. Comparisons were made with results from the Australian ITC Project, which surveyed 1017 daily smokers between July 2010 and May 2011 (Wave 8), and 1010 daily smokers between September 2011 and February 2012 (Wave 8.5). Participants of the Australian ITC Project were adult smokers who were recruited by random digit telephone dialling from within strata defined by jurisdiction and remoteness. ${ }^{26,27}$

The ITC Project sample mostly comprised those recontacted from previous survey waves, in addition to smokers who were newly recruited to replace those lost to follow-up (Wave $8,14.6 \%$; Wave $8.5,17.8 \%$ ). While baseline surveys were completed over the telephone, follow-up surveys could be self-administered online (Wave 8, 29.6\%; Wave 8.5, 32.1\%). Slightly different definitions of smokers between the TATS project and ITC Project surveys meant that only daily and weekly smoker categories were directly comparable. We have concentrated on daily smokers in our analyses.

\section{Outcome measures}

Survey questions were based on ITC Project surveys, particularly the Australian ITC Project surveys. The exact questions used for this article are presented in Appendix 1.

Eight questions measured attitudes towards smoking, all of which captured responses using a five-point scale from "strongly agree" to "strongly disagree" (plus a "don't know" response, which was later merged with "neither agree nor disagree"). Five of these questions are reported here for smokers, and three for recent quitters.

Two outcomes were used to assess quitting: wanting to quit, and having attempted to quit in the past year, which was derived from questions on ever having tried to quit and how long ago the most recent quit attempt occurred.

\section{Statistical analyses}

We summarised the TATS project and ITC Project survey results using descriptive statistics. ITC Project data were directly standardised to match the age and sex profile of Aboriginal and Torres Strait Islander smokers according to the 2008 NATSISS. Given that our sample was not randomly selected, we did not calculate standard errors for comparisons of percentages between our data and ITC Project data. Thus, these comparisons do not incorporate calculations for statistical significance, but consider differences that are large and meaningful.

For smokers, we used logistic regression to analyse the five attitudinal outcomes and two outcomes on quitting. Unadjusted odds ratios (ORs) are reported for the five personal attitudes (dichotomised), by daily smoking status, sociodemographic variables, and presence of tobacco control resources at the local health service. For the outcomes on quitting, we report adjusted ORs for the five personal attitudes, controlling for daily smoking status and sociodemographic variables. Stata 13 (StataCorp) survey [SVY] commands were used to adjust for the TATS project sampling design in all tests of association, using Stata's svyset command to identify the 35 project sites as clusters and the quotas based on age and sex as strata. ${ }^{28}$

Data for less than $1 \%$ of participants were excluded due to missing or refused responses. For the associations with wanting to quit, we excluded a further 79 participants $(4.8 \%)$ who did not know if they wanted to quit, and for associations with quitting in the past year, we excluded $21(1.3 \%)$ who did not know when their last quit attempt occurred (if ever).

\section{Results}

\section{Attitudes held by smokers}

\section{Comparison with ITC Project data}

Most attitudes among Aboriginal and Torres Strait Islander smokers were similar to those assessed for smokers in the general Australian population (Box 1). Most daily smokers reported regret about ever starting to smoke (TATS, 78\%; ITC, 81.8\%) and agreed that they spent too much money on cigarettes (TATS, 81\%; ITC, 83.6\%). A lower proportion of Aboriginal and Torres Strait Islander daily 
1 Attitudes towards smoking among smokers in the Australian population and a national sample of Aboriginal and Torres Strait Islander people*

\begin{tabular}{|c|c|c|c|}
\hline \multirow[b]{2}{*}{ Survey question and response } & \multirow{2}{*}{$\begin{array}{c}\text { Australian ITC } \text { Project }^{\dagger} \\
\text { Daily smokers, } \\
\%(95 \% \mathrm{Cl}) \\
\end{array}$} & \multicolumn{2}{|c|}{ Talking About The Smokes project ${ }^{\ddagger}$} \\
\hline & & $\begin{array}{l}\text { Daily smokers, \% } \\
\text { (frequency) }\end{array}$ & $\begin{array}{c}\text { Non-daily smokers, \% } \\
\text { (frequency) }\end{array}$ \\
\hline \multicolumn{4}{|c|}{ If you had to do it over again, you would not have started smoking } \\
\hline Strongly agree or agree & $81.8 \%(75.7 \%-86.6 \%)$ & $78 \%(1081)$ & $79 \%(197)$ \\
\hline Neither agree nor disagree & $6.8 \%(4.3 \%-10.7 \%)$ & $7 \%(102)$ & $9 \%(23)$ \\
\hline Disagree or strongly disagree & $11.4 \%(7.3 \%-17.3 \%)$ & $15 \%(200)$ & $12 \%(30)$ \\
\hline \multicolumn{4}{|c|}{ You spend too much money on cigarettes ${ }^{\natural}$} \\
\hline Strongly agree or agree & $83.6 \%(78.4 \%-87.6 \%)$ & $81 \%(1116)$ & $54 \%(134)$ \\
\hline Neither agree nor disagree & $7.4 \%(5.0 \%-11.0 \%)$ & $8 \%(110)$ & $11 \%(28)$ \\
\hline Disagree or strongly disagree & $9.0 \%(5.9 \%-13.5 \%)$ & $11 \%(156)$ & $35 \%(87)$ \\
\hline \multicolumn{4}{|l|}{ You enjoy smoking $\$$} \\
\hline Strongly agree or agree & $80.6 \%(75.8 \%-84.6 \%)$ & $65 \%(898)$ & $51 \%(127)$ \\
\hline Neither agree nor disagree & $10.1 \%(7.5 \%-13.6 \%)$ & $19 \%(261)$ & $20 \%(49)$ \\
\hline Disagree or strongly disagree & $9.3 \%(6.3 \%-13.4 \%)$ & $16 \%(223)$ & $29 \%(73)$ \\
\hline \multicolumn{4}{|c|}{ Smoking is an important part of your life $e^{\delta}$} \\
\hline Strongly agree or agree & $34.6 \%(29.8 \%-39.9 \%)$ & $32 \%(444)$ & $20 \%(50)$ \\
\hline Neither agree nor disagree & $27.4 \%(22.5 \%-33.0 \%)$ & $19 \%(268)$ & $12 \%(30)$ \\
\hline Disagree or strongly disagree & $37.9 \%(32.5 \%-43.6 \%)$ & $49 \%(670)$ & $68 \%(169)$ \\
\hline \multicolumn{4}{|c|}{ Smoking calms you down when you are stressed or upset ${ }^{\natural}$} \\
\hline Strongly agree or agree & $80.3 \%(75.5 \%-84.3 \%)$ & $83 \%(1143)$ & $70 \%(174)$ \\
\hline Neither agree nor disagree & $11.0 \%(7.7 \%-15.7 \%)$ & $9 \%(127)$ & $13 \%(33)$ \\
\hline Disagree or strongly disagree & $8.7 \%(6.6 \%-11.2 \%)$ & $8 \%(111)$ & $17 \%(42)$ \\
\hline
\end{tabular}

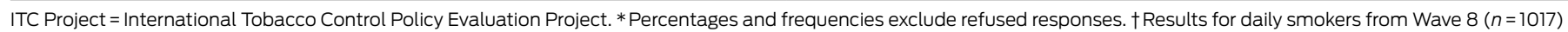
or Wave $8.5(n=1010)$ of the Australian ITC Project, directly standardised to the age and sex of Aboriginal and Torres Strait Islander smokers surveyed in the 2008 National Aboriginal and Torres Strait Islander Social Survey. $\ddagger$ Results for the baseline sample of Aboriginal and Torres Strait Islander daily smokers ( $n=1392$ ) and non-daily smokers

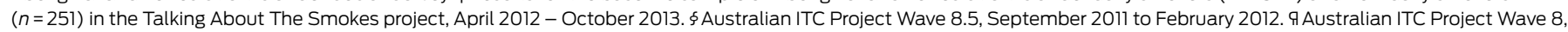
July 2010 to May 2011.

smokers (65\%) than those in the general Australian population (80.6\%) said they enjoyed smoking (Box 1). Though similar proportions of daily smokers agreed that smoking is an important part of their life (TATS, $32 \%$; ITC, $34.6 \%$ ), a higher proportion of Aboriginal and Torres Strait Islander respondents disagreed with this statement (TATS, 49\%; ITC, $37.9 \%$ ). A high proportion of daily smokers agreed that smoking calms them down when stressed or upset (TATS, 83\%; ITC, 80.3\%).

\section{Attitudes of Aboriginal and Torres Strait Islander smokers}

Non-daily smokers generally held less positive attitudes towards smoking (Appendix 2); compared with daily smokers, they were significantly less likely to say that they enjoy smoking (OR, 0.56; 95\% CI, $0.42-0.75 ; P<0.001)$, that smoking is an important part of their life (OR, $0.53 ; 95 \%$ CI, $0.35-0.81 ; P=0.004)$ and that smoking calms them down when stressed (OR, 0.48; 95\% CI, 0.35-0.67;
$P<0.001)$. Non-daily smokers were also less likely to report that they spend too much money on cigarettes (OR, 0.28; 95\% CI, 0.20-0.39; $P<0.001$ ).

There was little variation in smoker attitudes by sociodemographic and other factors (Appendix 2). Compared with the youngest smokers, those aged 35-44 years were less likely to say they enjoy smoking (OR, 0.64; 95\% CI, 0.43-0.93), whereas older smokers were more likely to report that smoking is an important part of their life $(P<0.001)$. Smokers from areas of the highest level of disadvantage were more likely to report that they enjoy smoking (OR, 1.66; 95\% CI, 1.192.30) compared with those from the least disadvantaged areas $(P=0.01)$. Smokers from regional areas (OR, 1.67; 95\% CI, 1.27-2.20) and remote or very remote areas (OR, 2.13; 95\% CI, 1.49-3.04) were also more likely than those from major cities to report that they enjoy smoking $(P<0.001)$. Smokers who were not in the labour force (OR, 1.78; 95\% CI, 1.32-2.38) were more likely to see smoking as an important part of their life than those who were employed $(P<0.001)$.

Attitudes about regretting ever starting to smoke, being calmed by smoking when stressed, and spending too much money on cigarettes did not vary according to sociodemographic indicators.

\section{Relationship of smoker attitudes with quitting}

The likelihood of wanting to quit or having attempted to quit in the past year was higher for Aboriginal and Torres Strait Islander smokers who regretted starting to smoke and those who said they spend too much money on cigarettes, and lower for smokers who said they enjoy smoking and those who reported that smoking is an important part of their life (Box 2).

\section{Attitudes held by recent quitters}

Ex-smokers who had quit within the past 12 months reported positive 
2 Association of personal attitudes towards smoking with wanting and attempting to quit in a national sample of Aboriginal and Torres Strait Islander smokers*

Want to quit

Attempted to quit in the past year

\begin{tabular}{|c|c|c|c|c|c|c|}
\hline \multirow[b]{2}{*}{ Attitude } & \multirow[b]{2}{*}{$\%$ (frequency) $^{\dagger}$} & \multirow[b]{2}{*}{ Adjusted OR $(95 \% \mathrm{CI})^{\ddagger}$} & \multirow[b]{2}{*}{$P^{\delta}$} & \multirow[b]{2}{*}{$\%$ (frequency) $^{\dagger}$} & \multirow[b]{2}{*}{ Adjusted OR $(95 \% \mathrm{Cl})^{\ddagger}$} & \multirow[b]{2}{*}{$P^{\S}$} \\
\hline & & & & & & \\
\hline \multicolumn{7}{|c|}{$\begin{array}{l}\text { If you had to do it over again, you would not } \\
\text { have started smoking }\end{array}$} \\
\hline Neutral or disagree & $52 \%(176)$ & 1.0 & $<0.001$ & $38 \%(131)$ & 1.0 & $<0.001$ \\
\hline Agree & $75 \%(907)$ & $2.79(1.96-3.97)$ & & $53 \%(662)$ & $1.84(1.37-2.48)$ & \\
\hline \multicolumn{7}{|c|}{ You spend too much money on cigarettes } \\
\hline Neutral or disagree & $59 \%(204)$ & 1.0 & $<0.001$ & $45 \%(167)$ & 1.0 & 0.02 \\
\hline Agree & $73 \%(879)$ & $2.22(1.59-3.10)$ & & $51 \%(626)$ & $1.41(1.06-1.88)$ & \\
\hline \multicolumn{7}{|l|}{ You enjoy smoking } \\
\hline Neutral or disagree & $85 \%(489)$ & 1.0 & $<0.001$ & $58 \%(348)$ & 1.0 & $<0.001$ \\
\hline Agree & $61 \%(594)$ & $0.29(0.21-0.42)$ & & $44 \%(445)$ & $0.56(0.44-0.70)$ & \\
\hline \multicolumn{7}{|c|}{ Smoking is an important part of your life } \\
\hline Neutral or disagree & $75 \%(805)$ & 1.0 & $<0.001$ & $53 \%(591)$ & 1.0 & 0.001 \\
\hline Agree & $59 \%(278)$ & $0.48(0.37-0.63)$ & & $41 \%(202)$ & $0.68(0.55-0.86)$ & \\
\hline \multicolumn{7}{|c|}{$\begin{array}{l}\text { Smoking calms you down when you are } \\
\text { stressed or upset }\end{array}$} \\
\hline Neutral or disagree & $70 \%(203)$ & 1.0 & 0.75 & $46 \%(140)$ & 1.0 & 0.09 \\
\hline Agree & $70 \%(880)$ & $1.06(0.75-1.51)$ & & $50 \%(653)$ & $1.28(0.97-1.69)$ & \\
\hline
\end{tabular}

3 Attitudes towards smoking and quitting among recent quitters in a national sample of Aboriginal and Torres Strait Islander people*

Survey question and response $\%$ (frequency) $^{\dagger}$

Since you quit you have more money

$\begin{array}{lc}\text { Strongly agree or agree } & 87 \%(68) \\ \text { Neither agree or disagree (or don't know) } & 8 \%(6) \\ \text { Disagree or strongly disagree } & 5 \%(4)\end{array}$

You can now cope with stress as well as you did when you were smoking

Strongly agree or agree

Neither agree or disagree (or don't know)

Disagree or strongly disagree

Your life is better now that you no longer smoke

Strongly agree or agree

$90 \%(70)$

Neither agree or disagree (or don't know)

$8 \%(6)$

$3 \%(2)$

Disagree or strongly disagree

* Results for the baseline sample of Aboriginal and Torres Strait Islander ex-smokers who had quit within past $\leqslant 12$ months $(n=78)$ in the Talking About The Smokes project. $†$ Percentages and frequencies exclude refused responses.

\section{Discussion}

Our results show that Aboriginal and Torres Strait Islander people were less likely than the general Australian population to report positive reasons to smoke and held similar views about the negative aspects of smoking. As negative attitudes to smoking were already common, approaches that seek to change these beliefs are not likely to affect Aboriginal and Torres Strait Islander smoking or quitting rates. In particular, levels of regret for ever starting to smoke were comparable to those seen globally. ${ }^{5,29}$ We hope this energises and reassures those in comprehensive primary health care settings who face the challenge of prioritising smoking cessation amid other, often pressing, demands. ${ }^{30}$

It is encouraging that a majority of smokers rejected the idea that smoking is an important part of their life, and that a lower proportion of Aboriginal and Torres Strait Islander smokers compared with those in the general Australian population said they enjoy smoking. As in other populations, smokers who agreed with statements about positive attributes of smoking were less interested in quitting and less likely to attempt to quit. ${ }^{10,31}$ The ITC Project has found that smokers who hold these positive attitudes are also less likely to quit successfully, but that part of this effect can be explained by differences in measures of nicotine dependence. ${ }^{10}$ However, factors that predict successful quitting sometimes differ from those that predict quit intentions and attempts. ${ }^{6,7}$ The complex relationships between attitudes, other factors and successful quitting is an important topic for future prospective research in this population.

Qualitative research has demonstrated broad recognition among Aboriginal and Torres Strait Islander peoples that stress is both a trigger for smoking and a common cause of relapse, ${ }^{14-17,19-21}$ consistent with international evidence on smoking for stress management. ${ }^{9,10}$ While we were surprised to find that those who believe smoking reduces their stress were no less motivated to quit, our outcomes were limited to quit attempts and not the success of such attempts. Connections between smoking and stress, or psychological reactions to stress, would benefit from further 
study using measures shown to be sensitive to the multiple life stressors and high levels of psychological distress experienced by Aboriginal and Torres Strait Islander peoples. ${ }^{32,33}$ Exploration of supports and strategies that enable successful quitting in the presence of these stressors is also indicated. Research on resilience to stress describes the pride associated with mastering the transition to becoming a non-smoker. ${ }^{16}$ In our results, most ex-smokers agreed that they cope with stress at least as well as they did when smoking and that their life is better now that they no longer smoke. The reduction in psychological distress that follows quitting is well documented. ${ }^{34,35}$ Health professionals and cessation resources could work towards extinguishing the myth that smoking reduces stress by replacing it with a more accurate and empowering message that exsmokers experience less stress and greater quality of life once they quit.

\section{Strengths and limitations}

This article provides a broadly nationally representative snapshot of attitudes towards smoking held by Aboriginal and Torres Strait Islander smokers. The use of single items to measure constructs can lack sensitivity but enabled us to enquire about a broad range of topics, using attitudinal and functional utility items that have established validity in other populations. ${ }^{36}$ While the validity of these items is yet to be established for Aboriginal and Torres Strait Islander peoples, comparable associations with quit-related outcomes provide some evidence of convergent validity. ${ }^{36}$ However, the limited number of closed-ended questions used here would not have captured the full range of attitudes held by Aboriginal and Torres Strait Islander smokers and may have missed important constructs.

Further, comparisons with ITC Project data must be made with a degree of caution. There is expert consensus that response styles are culturally moderated, meaning that the degree to which social desirability bias affects the tendency to agree or respond using scale extremities can vary according to respondent characteristics. ${ }^{36}$ Methods of recruitment and data collection also differ between the TATS and ITC projects, which may affect response biases present in each. However, the degree of variation to responses across the eight attitude items provides some evidence against any systematic response preference or bias in our data.

Finally, these results do not provide information about whether negative attitudes towards smoking precede quitting, or whether those who are already making quit attempts tend to develop more negative views about smoking. Our understanding of the likely direction of these relationships is informed by prospective research from other settings, which can be tested using longitudinal data from the follow-up of these baseline results.

With these limitations in mind, our findings add to our understanding of the context of smoking and quitting for Aboriginal and Torres Strait Islander peoples. The finding that their personal attitudes towards smoking are similar to those among the general Australian population, and appear to share the same motivating effects, suggests factors other than personal attitudes are likely to explain the high prevalence of smoking among Aboriginal and Torres Strait Islander people. Future research should consider the effect of structural factors, such as access to services that support quitting, intergenerational effects of colonisation and dispossession, levels of racism and psychological distress, and normalisation of smoking within Aboriginal and Torres Strait Islander social networks. . $^{17,19,22,37-39}$

Acknowledgements: The full list of acknowledgements is available in Appendix 3.

Competing interests: No relevant disclosures.

Provenance: Not commissioned; externally peer reviewed.

Received 31 Oct 2014, accepted 7 Apr 2015.

1 West R, Brown J. A theory of addiction, 2nd ed. Chichester, UK: John Wiley \& Sons, 2013: 229-253.

2 Borland R. Using CEOS to advance knowledge. In: Understanding hard to maintain behaviour change: a dual process approach. Chichester, UK: John Wiley \& Sons, 2014: 209-229.

3 Hyland A, Borland R, Li Q, et al. Individuallevel predictors of cessation behaviours among participants in the International Tobacco Control (ITC) Four Country Survey. Tob Control 2006; 15 Suppl 3: iii83-iii94.

4 Hosking W, Borland R, Yong HH, et al. The effects of smoking norms and attitudes on quitting intentions in Malaysia, Thailand and four Western nations: a cross-cultural comparison. Psychol Health 2009; 24: 95-107.

5 Fong GT, Hammond D, Laux FL, et al. The near-universal experience of regret among smokers in four countries: findings from the International Tobacco Control Policy Evaluation Survey. Nicotine Tob Res 2004; 6 Suppl 3: S341-S351.

6 Borland R, Yong HH, Balmford J, et al. Motivational factors predict quit attempts but not maintenance of smoking cessation: findings from the International Tobacco Control Four country project. Nicotine Tob Res 2010; 12 Suppl: S4-S11.

7 Vangeli E, Stapleton J, Smit ES, et al. Predictors of attempts to stop smoking and their success in adult general population samples: a systematic review. Addiction 2011; 106: 2110-2121.

8 Fotuhi O, Fong GT, Zanna MP, et al. Patterns of cognitive dissonancereducing beliefs among smokers: a longitudinal analysis from the International Tobacco Control (ITC) Four Country Survey. Tob Control 2013; 22: 52-58.

9 Herd N, Borland R, Hyland A. Predictors of smoking relapse by duration of abstinence: findings from the International Tobacco Control (ITC) Four Country Survey. Addiction 2009; 104: 2088-2099.

10 Yong HH, Borland R. Functional beliefs about smoking and quitting activity among adult smokers in four countries: findings from the International Tobacco Control Four-Country Survey. Health Psychol 2008; 27: S216-S223.

11 Poland B, Frohlich K, Haines RJ, et al. The social context of smoking: the next frontier in tobacco control? Tob Control 2006; 15: 59-63.

12 Australian Bureau of Statistics. Australian Aboriginal and Torres Strait Islander Health Survey: updated results, 2012-13. Canberra: ABS, 2014. (ABS Cat No. 4727.0.55.006.)

13 Campbell D. Economic rationality in choosing between short-term bad-health choices and longer-term good-health choices. Int J Environ Res Public Health 2013; 10: 5971-5988. 
14 Wood L, France K, Hunt K, et al. Indigenous women and smoking during pregnancy: knowledge, cultural contexts and barriers to cessation. Soc Sci Med 2008; 66: 2378-2389.

15 Gould GS, Munn J, Avuri S, et al. "Nobody smokes in the house if there's a new baby in it": Aboriginal perspectives on tobacco smoking in pregnancy and in the household in regional NSW Australia. Women Birth 2013; 26: 246-253.

16 Bond C, Brough M, Spurling G, Hayman N. "It had to be my choice": Indigenous smoking cessation and negotiations of risk, resistance and resilience. Health Risk Soc 2012; 14: 565-581.

17 Lindorff K. Tobacco: time for action. National Aboriginal and Torres Strait Islander Tobacco Control Project. Final report. Canberra: National Aboriginal Community Controlled Health Organisation, 2002.

18 DiGiacomo M, Davidson PM, Davison J, et al. Stressful life events, resources, and access: key considerations in quitting smoking at an Aboriginal Medical Service. Aust NZ J Public Health 2007; 31: 174-176.

19 Johnston V, Thomas DP. Smoking behaviours in a remote Australian indigenous community: The influence of family and other factors. Soc Sci Med 2008; 67: 1708-1716.

20 Dawson AP, Cargo M, Stewart H, et al. "I know it's bad for me and yet I do it": exploring the factors that perpetuate smoking in Aboriginal Health Workers - a qualitative study. BMC Health Serv Res 2012; 12: 102
21 Passey ME, Gale JT, Sanson-Fisher RW. "It's almost expected": rural Australian Aboriginal women's reflections on smoking initiation and maintenance: a qualitative study. BMC Womens Health 2011; 11: 55.

22 Briggs VL, Lindorff KJ, Ivers RG. Aboriginal and Torres Strait Islander Australians and tobacco. Tob Control 2003; 12 Suppl 2: ii5-ii8.

23 Australian Institute of Health and Welfare. National Drug Strategy Household Survey report, 2010. Canberra: AlHW, 2011. (AlHW Cat. No. PHE 145; Drug Statistics Series No. 25.)

24 Thomas DP, Briggs VL, Couzos S, et al. Research methods of Talking About The Smokes: an International Tobacco Control Policy Evaluation Project study with Aboriginal and Torres Strait Islander Australians. Med J Aust 2015; 202 (10 Suppl): S5-S12.

25 Couzos S, Nicholson AK, Hunt JM, et al. Talking About The Smokes: a large-scale, community-based participatory research project. Med J Aust 2015; 202 (10 Suppl): S13-S19.

26 Thompson ME, Fong GT, Hammond D, et al. Methods of the International Tobacco Control (ITC) Four Country Survey. Tob Control 2006; 15 Suppl 3: iiil2-iiil8.

27 International Tobacco Control Policy Evaluation Project. Four Country Project: Waves 2-8 technical report. Waterloo, Canada: University of Waterloo, 2011 [updated Jan 2015]. http://www. itcproject.org/files/Report_Publications/
Technical_Report/4c-w28-tech-reportsept2011.pdf (accessed Mar 2015).

28 StataCorp. Stata survey data reference manual: release 13. College Station, Tex: Stata Press, 2013. http://www.stata.com/ manuals13/svy.pdf (accessed Apr 2015).

29 Sansone N, Fong GT, Lee WB, et al. Comparing the experience of regret and its predictors among smokers in four Asian countries: findings from the ITC surveys in Thailand, South Korea, Malaysia, and China. Nicotine Tob Res 2013; 15: 1663-1672.

30 Johnston V, Thomas DP. What works in Indigenous tobacco control? The perceptions of remote Indigenous community members and health staff. Health Promot J Austr 2010; 21: 45-50.

31 Fidler JA, West R. Enjoyment of smoking and urges to smoke as predictors of attempts and success of attempts to stop smoking: A longitudinal study. Drug Alcohol Depend 2011; 115: 30-34.

32 Stevens M, Paradies Y. Changes in exposure to 'life stressors' in the Aboriginal and Torres Strait Islander population, 2002 to 2008. BMC Public Health 2014; 14: 144.

33 Australian Bureau of Statistics. Australian Aboriginal and Torres Strait Islander Health Survey: first results, Australia, 2012-13. Canberra: ABS, 2013. (ABS Cat No. 4727.0.55.001.)

34 McDermott MS, Marteau TM, Hollands GJ, et al. Change in anxiety following successful and unsuccessful attempts at smoking cessation: cohort study. $\mathrm{Br} J$ Psychiatry 2013; 202: 62-67.

35 Leung J, Gartner C, Dobson A, et al. Psychological distress is associated with tobacco smoking and quitting behaviour in the Australian population: evidence from national cross-sectional surveys. Aust N Z J Psychiatry 2011; 45: 170-178.

36 International Agency for Research on Cancer. IARC handbooks of cancer prevention: tobacco control. Volume 12. Methods for evaluating tobacco control policies. Lyon: IARC, 2008: 59-74, 107-122.

37 Ivers R. Anti-tobacco programs for Aboriginal and Torres Strait Islander people. Produced for the Closing the Gap Clearinghouse. Canberra: Australian Institute of Health and Welfare; and Melbourne: Australian Institute of Family Studies, 2011.

38 Paradies Y. A systematic review of empirical research on self-reported racism and health. Int J Epidemiol 2006; 35: 888-901.

39 Thomas D, Briggs V, Anderson IP, Cunningham J. The social determinants of being an Indigenous non-smoker. Aust N Z J Public Health 2008; 32: 110-116. .
Project staff and leadership group meeting at NACCHO (National Aboriginal Community Controlled Organisation) offices, June 2014, Canberra, Australian Capital Territory. 